\title{
The extracellular matrix protein EMILIN1 silences the RAS-ERK pathway via $\alpha 4 \beta 1$ integrin and decreases tumor cell growth
}

\author{
Teresa Maria Elisa Modica ${ }^{1}$, Orlando Maiorani ${ }^{1}$, Giulio Sartori ${ }^{1}$, Eliana Pivetta ${ }^{1}$, \\ Roberto Doliana ${ }^{1}$, Alessandra Capuano ${ }^{1}$, Alfonso Colombatti ${ }^{1}$, Paola Spessotto ${ }^{1}$ \\ ${ }^{1}$ Department of Translational Research, Experimental Oncology 2 Division, CRO Aviano, National Cancer Institute, Aviano, \\ PN 33081, Italy. \\ Correspondence to: Alfonso Colombatti, email: acolombatti@cro.it \\ Keywords: extracellular matrix, gClq domain, $\alpha 4 \beta 1$ integrin, RAS-ERK pathway, proliferation \\ Abbreviations: ECM, extracellular matrix \\ Received: October 26, $2016 \quad$ Accepted: January 09, $2017 \quad$ Published: February 03, 2017 \\ Copyright: Modica et al. This is an open-access article distributed under the terms of the Creative Commons Attribution License \\ (CC-BY), which permits unrestricted use, distribution, and reproduction in any medium, provided the original author and source \\ are credited.
}

\section{ABSTRACT}

The extracellular matrix plays a fundamental role in physiological and pathological proliferation. It exerts its function through a signal cascade starting from the integrins that take direct contact with matrix constituents most of which behave as proproliferative clues. On the contrary, EMILIN1, a glycoprotein interacting with the $\alpha 4 \beta 1$ integrin through its gC1q domain, plays a paradigmatic anti-proliferative role. Here, we demonstrate that the EMILIN1-a4 interaction de-activates the MAPK pathway through HRas. Epithelial cells expressing endogenous $\alpha 4$ integrin and persistently plated on gC1q inhibited pERK1/2 increasing HRasGTP and especially the HRasGTP ubiquitinated form (HRasGTP-Ub). The drug salirasib reversed this effect. In addition, only the gC1q-ligated $\alpha 4$ integrin chain co-immunoprecipitated the ubiquitinated HRas. Only epithelial cells transfected with the wild type form of the $\alpha 4$ integrin chain showed the EMILIN1/ $\alpha 4 \beta 1 / H R a s / p E R K 1 / 2$ link, whereas cells transfected with a $\alpha 4$ integrin chain carrying a truncated cytoplasmic tail had no effect. In this study we unveiled the pathway activated by the gC1q domain of EMILIN1 through $\alpha 4 \beta 1$ integrin engagement and leading to the decrease of proliferation in an epithelial system.

\section{INTRODUCTION}

Integrins are heterodimeric cell membrane receptors which mediate cell interaction with the extracellular matrix (ECM). The integrins sense the composition and the mechanical tension within the pericellular milieu, and transmit this information intracellularly to signalling pathways which regulate cell fate by influencing cellular motility, apoptosis, differentiation as well as cell proliferation [1]. Upon engagement integrins rapidly activate signaling pathways mediated by their cytoplasmic domains and proteins with enzymatic activities like RasGTPases are recruited to the sites of cell adhesion to ECM. Integrin engagement by ECM, besides activating the RAS/ERK pathway, also can lead to mobilization of intracellular $\mathrm{Ca}^{2+}$ and influx from the extracellular space [2, 3]. While the early events upon integrin engagement have been deeply investigated, less known are the downstream consequences during persistent cell adhesion. In most cell types the ERK pathway which is activated by RAS is one of the key pathways required to trigger cell proliferation. In order to exert its function RAS is farnesylated and then it associates with the plasma membranes [4]. RAS has the inherent ability to undergo conformational changes and functions as a molecular switch that catalyzes the hydrolysis of GTP returning it to the inactive GDP-bound state [5]. Among RAS inhibitors shown to be promising in clinical trials [6], salirasib, that is a farnesylthiosalicylic acid specific H-RAS inhibitor, dislodges the RAS isoforms from their membrane-anchoring sites, thereby preventing the activation of the RAS signaling cascade [7, 8].

EMILIN1 (Elastic Microfibril Interface Located ProteIN) is a homotrimeric ECM multidomain glycoprotein associated with elastic fibers [9] and particularly abundant in skin. EMILIN1 is characterized by a region homologous to the globular domain of $\mathrm{Clq}$ ( $\mathrm{gClq}$ domain) 
at the C-terminal end $[10,11]$ involved in EMILIN1 oligomerization [12] and in cell adhesion and migration via interaction with the $\alpha 4 \beta 1$ integrin [13]. To investigate the role of EMILIN1 in vivo we generated $\mathrm{KO}$ mice and found that the lack of EMILIN1 results in: i) a mild phenotype of lymphatic capillaries [14] and vessels [15, 16] with increased lymphatic endothelial cell proliferation and ii) a skin hyperproliferative phenotype [17].

Ligand-activated integrins in general positively regulate cell growth [18-20]. In contrast, signals emanating from EMILIN1-ligated $\alpha 4 \beta 1$ integrin are anti-proliferative due to the increased levels of PTEN and decrease of pEKR1/2 [17]. However, the pathway(s) through which integrin-bound EMILIN1 exerts its negative regulatory function on cell proliferation remain(s) to be fully clarified. For instance, the role and the link between $\alpha 4 \beta 1$ and the small GTPases has not been determined yet.

In the present study, in order to mimic the in vivo conditions of cell-ECM interaction, we used a persistent cell adhesion approach to further investigate how the $\alpha 4 \beta 1 /$ EMILIN1 pair controls cell proliferation. We found that this is exerted via downmodulation of the HRas pathway through the HRasGTP ubiquitination.

\section{RESULTS}

\section{Downstream effects of persistent cell adhesion to $\mathrm{gC1q}$}

Phosphorylation of FAK(Tyr925) generates a binding site for $\mathrm{SH} 2$ bearing molecules and triggers a RAS-dependent activation of the MAP kinase pathway [21]. In HaCat keratinocytes persistently adherent to gC1q (i.e. after $24 \mathrm{~h}$ adhesion) FAK(Tyr925) resulted increased if compared to polylysine attachment, whereas FAK(Tyr397) did not change (Figure 1A). On the contrary, pERK1/2 was dramatically reduced on $\mathrm{gClq}$ at these late times of adhesion. To test if the active form of HRas (HRasGTP)

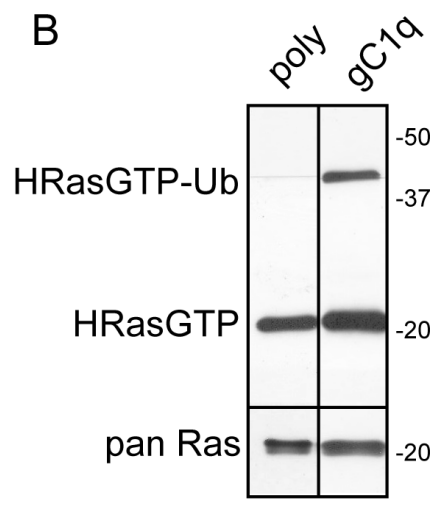

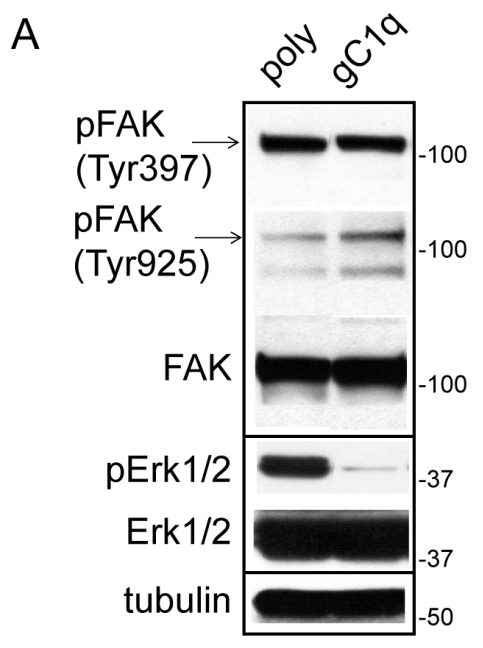

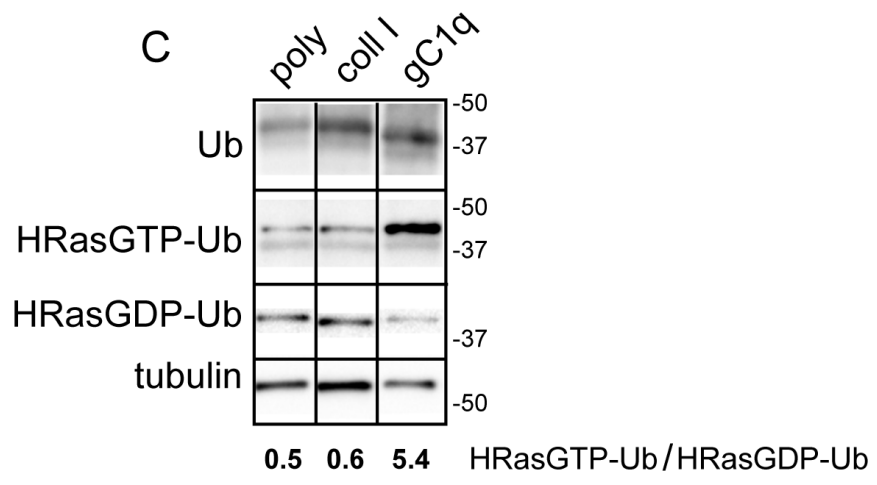

Figure 1: Persistent adhesion to gC1q downmodulates pERK1/2 and upregulates "HRasGTP-Ub". A. HaCat cells were lysed 24 hours after plating on polylysine (poly) or $\mathrm{gClq}$ coated plates. The blots were incubated with the indicated antibodies. Tubulin was used as loading control. B. Western blot analysis of proteins extracted from HaCat cells 24 hours after plating on polylysine (poly) or gC1q and incubated on a Raf-GST resin. Pan Ras was used to normalize loading. C. Western blot analysis of proteins extracted from HaCat cells 24 hours after plating on polylysine (poly), collagen type I or gC1q and incubated on a Raf-GST resin. Tubulin was used as loading control. 
was involved in cellular signals triggered by EMILIN1/ gC1q, first a HRasGTP pull-down assay was performed on HaCat cells plated on $\mathrm{gClq}$ or polylysine and analyzed $24 \mathrm{~h}$ after plating. HRasGTP increased in cells plated on gC1q compared to polylysine (Figure 1B).

In addition to the HRasGTP $21 \mathrm{kDa}$ band, an upper band of about $40 \mathrm{kDa}$ was detected by the anti HRas antibody (Figure 1B). Beside the canonical $21 \mathrm{kDa}$, RAS proteins display a plethora of faster and slower bands corresponding to the post-translational modified forms or to the mono- $(30 \mathrm{kDa})$ and di-ubiquitinated (40 $\mathrm{kDa}$ ) forms, respectively [22-25]. In our experiments the intensity of the $40 \mathrm{kDa}$ band, corresponding to the di-ubiquitinated HRasGTP (HRasGTP-Ub) form, was several-fold higher on $\mathrm{gClq}$ compared to polylysine, suggesting that, following $\alpha 4 \beta 1$ integrin activation as a consequence of cell adhesion to gC1q, HRasGTP could be ubiquitinated.

\section{The HRas-ERK1/2 pathway is inactivated via the $\alpha 4$ integrin chain}

To determine if the downstream consequences of cell adhesion to $\mathrm{gClq}$ were dependent on a mechanism specifically due to the ligation of the $\alpha 4 \beta 1$ integrin, we compared the extent of di-ubiquitinated HRasGTP in cells adherent to $\mathrm{gClq}$ to that detected in cells adherent to collagen type I that uses a different integrin as cellular receptor. As depicted in Figure $1 \mathrm{C}$ both the anti ubiquitin antibody as well as the anti HRas antibody recognized proteins whose migration corresponded to the HRasGTP di-ubiquitinated form. HRasGTP-Ub was 10 times less in cells adherent to polylysine as well as to collagen type I compared to gClq (Figure 1C), suggesting that the $\alpha 4$-dependent signaling was qualitatively/quantitatively distinct and specific. Accordingly, while the ratio of HRasGTP-Ub/HRasGDP-Ub was about 0.5 in cells adherent to either polylysine or collagen type I, this ratio was 10 -fold in cells adherent to $\mathrm{gClq}$, indicating that in $\alpha 4$-dependent cell adhesion there is a specific switch from RasGDP to RasGTP.

\section{The gC1q ligated $\alpha 4$ integrin chain is physically linked to HRas and controls cell growth}

To proof the physiological link between cell adhesion via the $\alpha 4 \beta 1$ integrin and HRas we used HaCat cells that endogenously express the $\alpha 4$ integrin chain. We confirmed that the adhesion of HaCat cells to the $\mathrm{gClq}$ or the collagen type I ligands was due to the $\alpha 4 \beta 1$ or the $\alpha 2 \beta 1$ integrins, respectively, by performing cell adhesion in the presence of the specific integrin blocking antibodies. Thus, the $\alpha 4 \beta 1 \mathrm{mAb}$ greatly reduced cell adhesion to $\mathrm{gClq}$ and the $\alpha 2 \beta 1 \mathrm{mAb}$ fully inhibited cell adhesion to collagen type I (Figure 2A).
Cells were placed on polylysine, collagen type I, or $\mathrm{gC} 1 \mathrm{q}$ for 24 hours and at the end of the incubation the cells lysates were immunoprecipitated with the a4 antibody and immunoblotted with anti HRas antibody. As expected, the $\alpha 4$ integrin chain was immunoprecipitated from cells adherent on each ligand; however, the ubiquitinated form of HRas (40 kDa mass) co-immunoprecipitated with the $\alpha 4$ integrin chain only in cells adhered to gC1q (Figure 2B). In fact, a band at the expected molecular mass was detected in the lysate and in the unbound cell lysate when probed with anti HRas antibody. Here, the HRasGTP and HRasGDP ubiquitinated forms cannot be distinguished since the lysates were co-immunoprecipitated and not pulled down for HRasGTP. However, as shown in Figure 1C where the amount of HRasGTP-Ub is much higher than the amount of HRasGDP-Ub, it is very likely that the coimmunoprecipitated HRas-Ub, in cells adhered to $\mathrm{gClq}$, is primarily due to the HRasGTP membrane-bound form.

To demonstrate if this pathway (HRasGTP $\rightarrow$ HRasGTP-Ub $\rightarrow$ pERK1/2) was directly linked to the $\alpha 4$ integrin chain, we selected the HT29 and SW480 cell lines that were negative for $\alpha 4 \beta 1$ and positive for $\alpha 2 \beta 1$ integrin (Figure 3A). Both cell lines were then stably transfected with either the wild type or an $\alpha 4$ integrin chain deleted of the intracytoplasmic sequences (Figure 3B). For the following experiments only cells that resulted at least 95\% positive for the expression of the $\alpha 4$ integrin chain were used. Both HT29 and SW480 transfected with either the wild type or the deleted $\alpha 4$ form were able to adhere to $\mathrm{gC} 1 \mathrm{q}$ although HT29 cells were more efficient than SW480 cells as the percentage of adhesion to $\mathrm{gC1q}$ was $90 \%$ and $60 \%$, respectively (Figure $3 \mathrm{C}$ and $3 \mathrm{D}$ ). Thus, for the following experiments we selected HT29 cells. Several clones transfected with either the wild type or the mutant $\alpha 4$ integrin chain were selected and the clones in which the $\alpha 4$ cell surface expression was more stable were further used. We measured the proliferative capacity of the transfected cells grown on collagen type I or EMILIN1/ $\mathrm{gClq}$ and found that the proliferation rate (measured as either normalized cell index or doubling time) of the cells transfected with either the wild type or the mutated $\alpha 4$ form was very similar on collagen type I. On the contrary, the proliferation rate was significantly lower on the full length EMILIN1 or $\mathrm{gClq}$ in cells transfected with the wild type $\alpha 4$ integrin chain compared to cells transfected with the deleted form in which the proliferation was not affected at all (Figures $4 \mathrm{~A}$ and 4B). These results show that the downstream signaling leading to reduced proliferation following $\alpha 4 \beta 1$-dependent cell adhesion to the EMILIN1/gC1q ligand depended on a fully functional $\alpha 4$ integrin chain. To link the proliferative and clonogenic capacity to the $\alpha 4 \beta 1$ integrin-dependent HRas activity we placed HT29 transfected clones in agar in the presence or in the absence of soluble gC1q. Whereas the colonies 
of the cells transfected with the wild type $\alpha 4$ integrin chain were significantly less in the presence of $\mathrm{gClq}$ (Figure 4C), the colonies of HT29 transfected with the mutant $\alpha 4$ integrin grew to the same number under all the experimental conditions (Figure 4D).

Moreover, the analysis of extracts from HT29 cells showed that the ratio of HRasGTP-Ub/HRasGDP-Ub in cells stably transfected with the wild type $\alpha 4$ integrin chain and adherent on collagen type I for $24 \mathrm{~h}$ was around 1.0 ; on the contrary and in analogy with data obtained on HaCat cells (see Figure 1C), this ratio was around 4.0 in cells adherent on $\mathrm{gClq}$ (Figure 4E). Our explanation is that after its activation HRas-GTP was directed towards ubiquitination. The ratio of HRasGTP-Ub/HRasGDP$\mathrm{Ub}$ in cells transfected with the deleted $\alpha 4$ integrin chain and adherent on $\mathrm{gClq}$ decreased accordingly compared to cells transfected with the wild type $\alpha 4$ integrin chain (Figure 4E), confirming that this pathway depended on the presence of a fully functional $\alpha 4$ integrin chain.

To prevent HRas pathway activation we interfered with the membrane anchoring of HRas after its farnesylation by treating cells with salirasib. Accordingly, after salirasib treatment both HRasGTP as well as the HRasGTP-Ub forms were detected neither in cell adherent to $\mathrm{gC} 1 \mathrm{q}$ nor to polylysine (Figure 5A).

Integrin engagement by ECM constituents leads to changes of $\mathrm{Ca}^{2+}$ levels by internal release and external influx that are responsible for controlling a plethora of cellular processes [2, 26-28]. Thus, FLUO-4 AM was loaded in $\mathrm{HaCat}$ cells to determine if there was any variation of cytosolic $\mathrm{Ca}^{2+}$ levels during the modulation of the HRasGTP/GDP cycling. Cells persistently plated
A

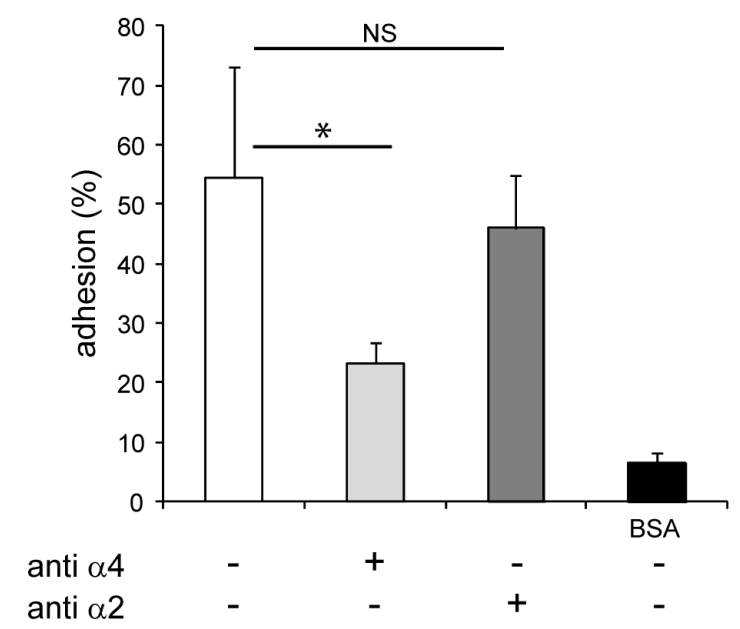

coll I

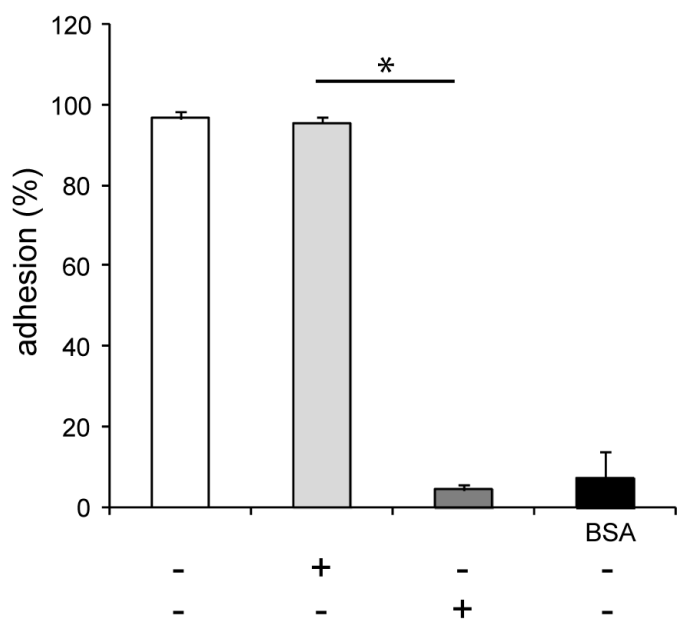

B

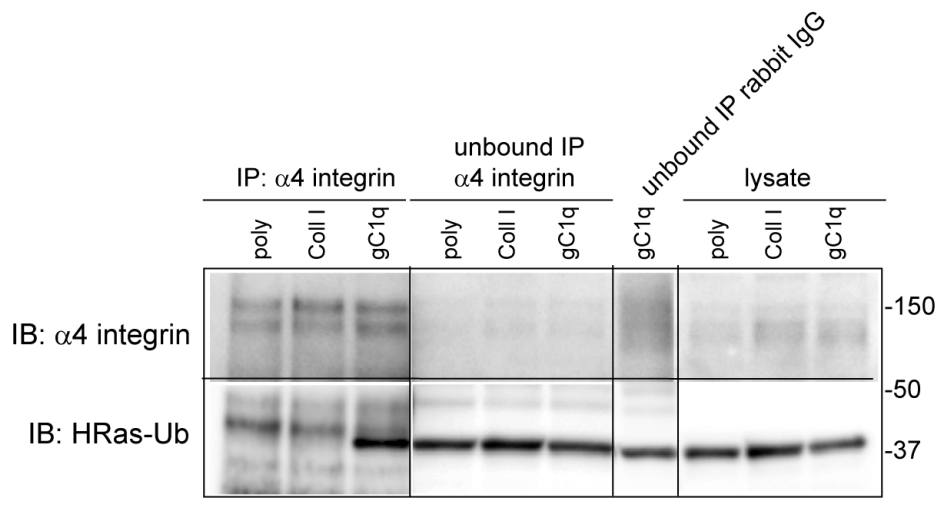

Figure 2: HRas-Ub is co-immunoprecipitated with the $\alpha \mathbf{4}$ integrin chain. A. Cell adhesion (CAFCA assay) of HaCat cells to $\mathrm{gClq}$ or collagen type I (Coll I) or BSA as negative control. The indicated antibodies were used to block the specific integrin binding. B. HaCat cells were lysed 24 hours after plating on polylysine (poly), Coll I or gC1q coated plates. Lysates were immunoprecipitated with the $\alpha 4$ antibody and immunoblotted with anti $\alpha 4$ antibody and anti HRas antibody. 
A

\begin{tabular}{|c|c|c|}
\hline & HT29 & SW480 \\
\hline$\alpha 1$ & $0 \%$ & $14 \%$ \\
\hline$\alpha 2$ & $97 \%$ & $95 \%$ \\
\hline$\alpha 3$ & $45 \%$ & $90 \%$ \\
\hline$\alpha 4$ & $0 \%$ & $0 \%$ \\
\hline$\alpha 5$ & $0 \%$ & $81 \%$ \\
\hline$\alpha 6$ & - & $97 \%$ \\
\hline$\alpha \mathrm{v}$ & $10 \%$ & - \\
\hline
\end{tabular}

B

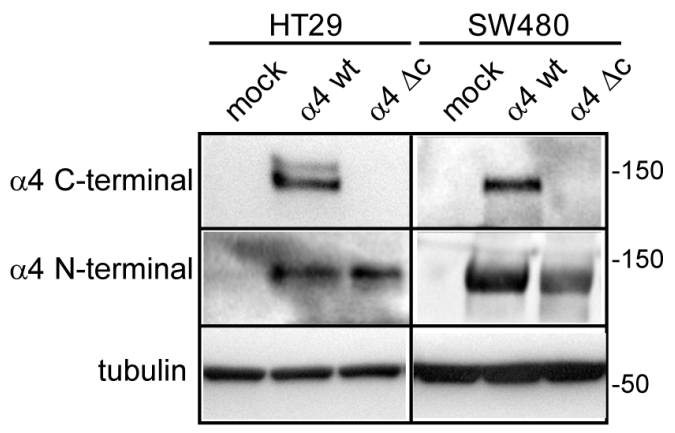

C

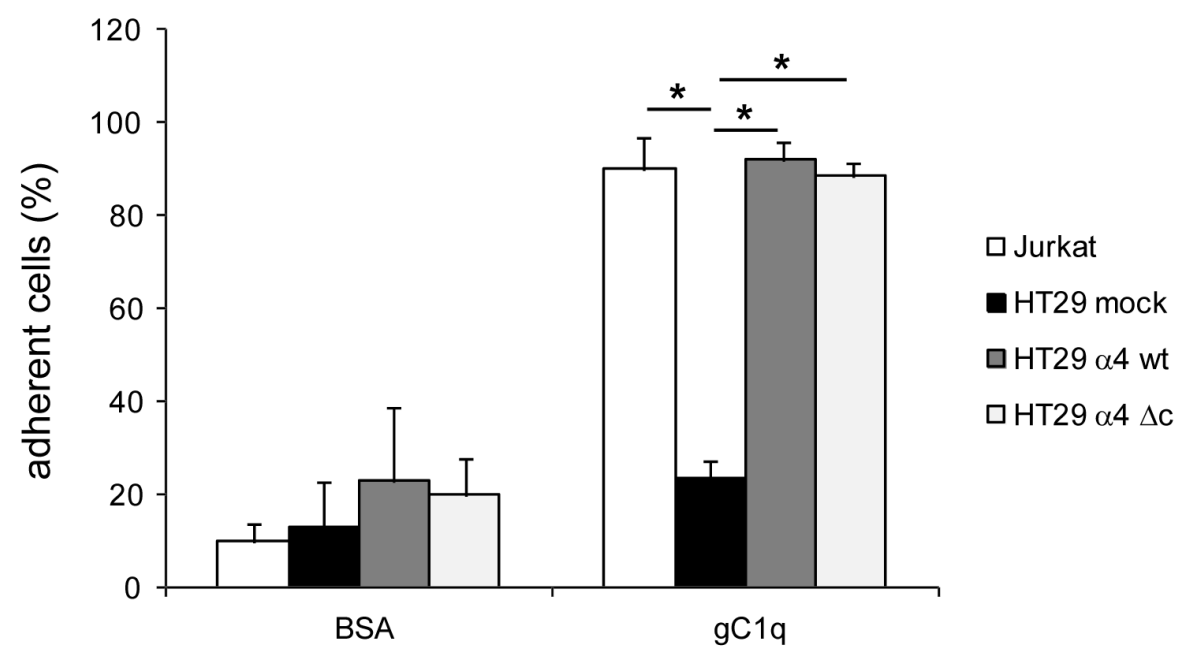

D

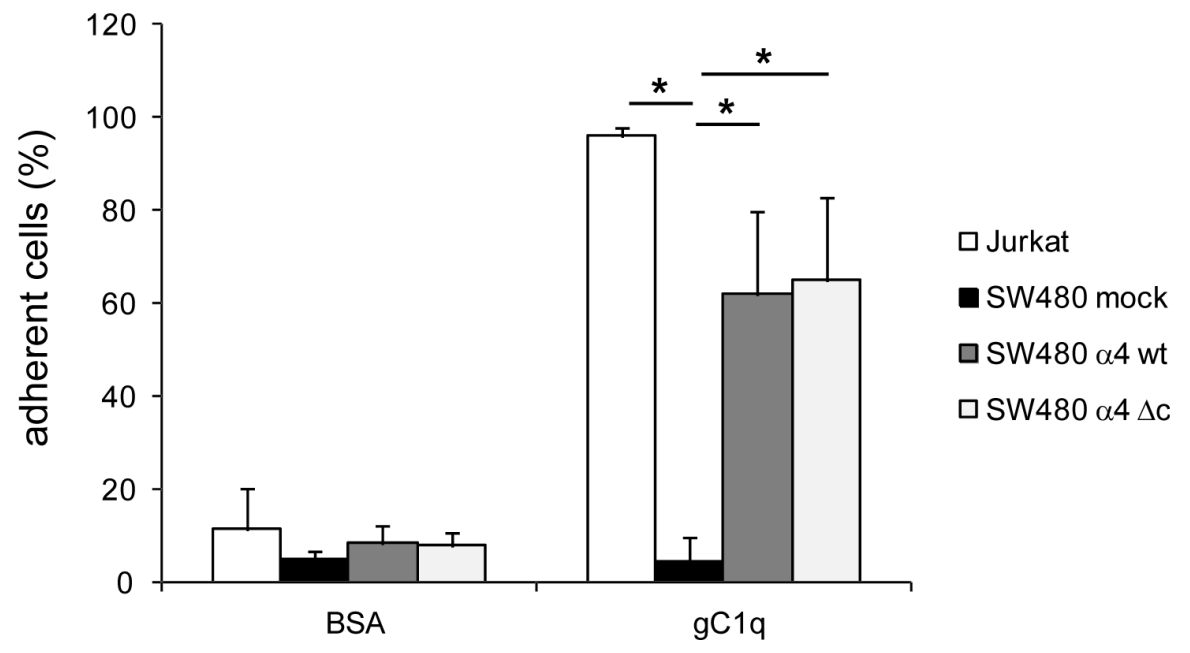

Figure 3: Cells adhere to gC1q through both wt and truncated $\alpha 4$ integrin chain. A. Endogenous integrin expression panel of HT29 and SW480 cells. B. Western blot detection of $\alpha 4$ integrin chain in HT29 and SW480 mock cells, wild type (wt) or truncated $(\Delta \mathrm{c}) \alpha 4$ integrin chain transfected HT29 and SW480 cells. C, D. HT29 and SW480 cells transfected with the wild type (wt) or truncated $(\Delta \mathrm{c}) \alpha 4$ integrin chain were allowed to adhere to $\mathrm{gClq}$ or BSA as control in CAFCA miniplates. Jurkat cells and mock cells were used as positive and negative controls of adhesion respectively. Data are expressed as the means $\pm \mathrm{SD}$ of $\mathrm{n}=3$ independent experiments with $\mathrm{n}=$ 6 replicates. *, $\mathrm{P}<0.05$. 
on polylysine exhibited a higher cytoplasmic amount of $\mathrm{Ca}^{2+}$ respect to cells plated on $\mathrm{gClq}$ (Figure 5B). When DMSO, that is used as vehicle of salirasib, was added to the cells as control, the cytoplasmic $\mathrm{Ca}^{2+}$ levels were changed, i.e. very low in cells persistently adherent to polylysine and, on the contrary, high in cells adherent to gC1q (Figure 5B). DMSO increased the $40 \mathrm{kDa}$ band, likely the di-ubiquitinated HRasGTP (HRasGTP-Ub), in cells adherent to polylysine (see Figure 1B), whereas this band disappeared in cells adherent to $\mathrm{gClq}$ (Figure
A
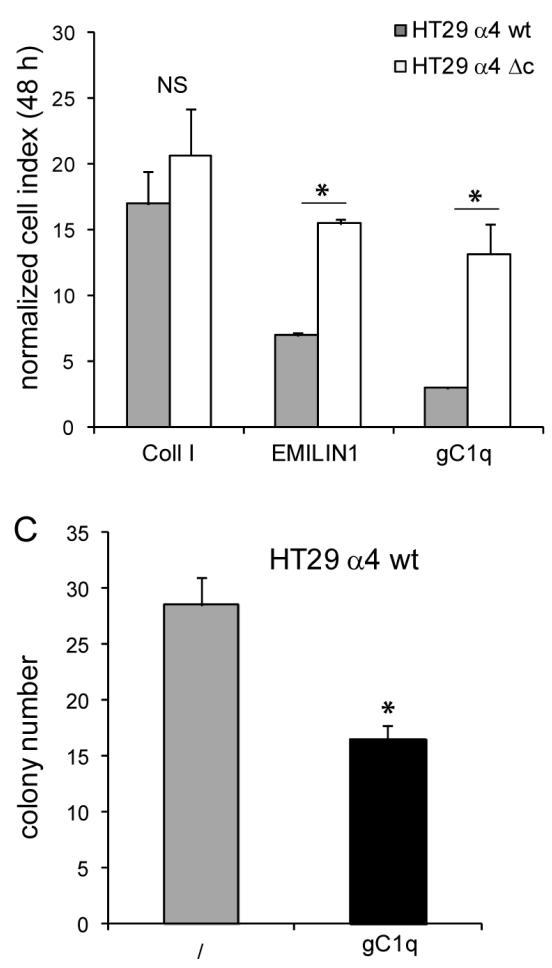

B
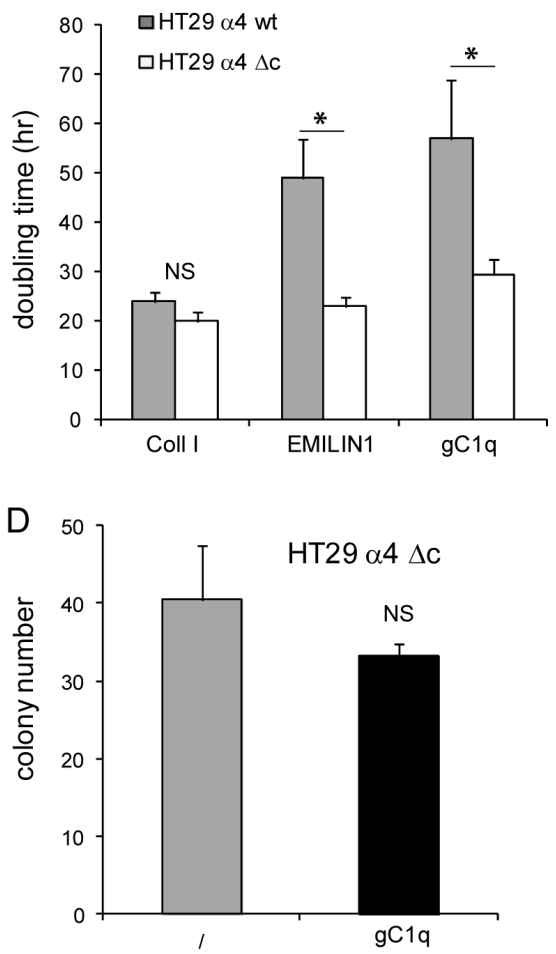

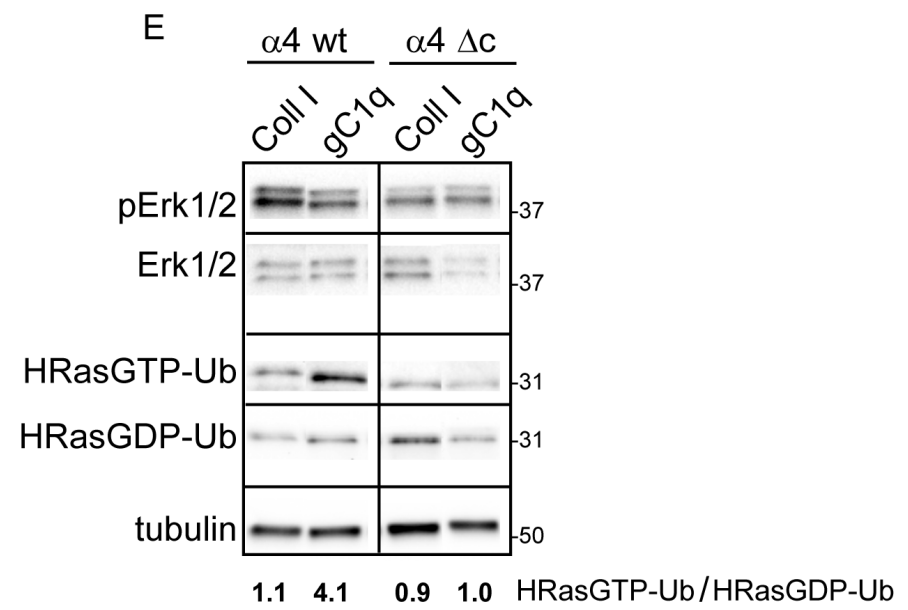

Figure 4: Cells growth is decreased by gC1q. Cellular growth of HT29 cells transfected with the wild type (wt) or the deleted ( $\Delta \mathrm{c})$ $\alpha 4$ integrin chain and plated on collagen type I (Coll I), EMILIN1, or gC1q expressed as either normalized cell index A. or doubling time B. and calculated as the mean \pm SD from $n=3$ experiments with $n=6$ replicates. Cells were allowed to proliferate for 48 hours. Cell index curves were then normalized (normalized cell index) to the point corresponding to 1 hour after plating (maximum cellular adhesion) in order to express proliferation ability independently from attachment to a particular substrate. C. HT29 cells transfected with the wild type (wt) or $\mathbf{D}$. the deleted $(\Delta \mathrm{c}) \alpha 4$ integrin chain and plated in $0.4 \%$ agar in the presence or in the absence of gC1q. E. Modulation of HRas$\mathrm{Ub}$ and pERK1/2 in $\alpha 4$ integrin chain transfected HT29 cells. HT29 cells were lysed 24 hours after plating on collagene type I (Coll I) or $\mathrm{gClq}$ coated plates. The blots were incubated with the indicated antibodies (see under Material and Methods). Tubulin was used as loading control. Cell lysates were pulled down on a Raf-GST resin to isolate HRasGTP-Ub. 
5A). Concomitantly, DMSO upregulated pERK1/2 in cells plated on $\mathrm{gC} 1 \mathrm{q}$, respect to polylysine (Figure 5C). On the other hand, salirasib reverted the downstream effects on both types of coatings respect to the DMSO alone. Of note the finding that the levels of pERK $1 / 2$ showed an inverse correlation with the $40 \mathrm{kDa}$ band intensity.

We then investigated if the inhibition of HRas membrane anchoring and activation by salirasib affected downstream signaling related to cell proliferation. While there was no significant effect on pFAK levels (Figure $5 \mathrm{C})$, the phosphorylation of ERK $1 / 2$ was increased on polylysine when HRasGTP was inibited by salirasib; in contrast, this treatment decreased pERK $1 / 2$ levels in cells adherent to $\mathrm{gC} 1 \mathrm{q}$ respect to control (Figure 5C). The treatment with salirasib greatly decreased ubiquitination of HRasGTP and increased cytosolic HRas (HRasGDP) on cell plated on either polylysine or gC1q (Figure 5D).

The number of colonies grown in agar of HT29 cells transfected with the wild type $\alpha 4$ integrin chain was significantly reduced only when plated in the presence of gC1q (Figure 6). The rescue effect by salirasib was not observed under all other conditions, i.e. salirasib and cells transfected with the truncated $\alpha 4$ integrin chain, DMSO with both types of cells. This demonstrated that, by knocking down HRasGTP and thus HRasGTP-Ub, the

A

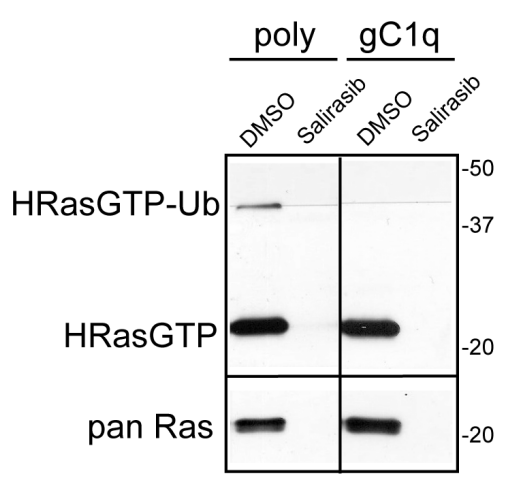

B

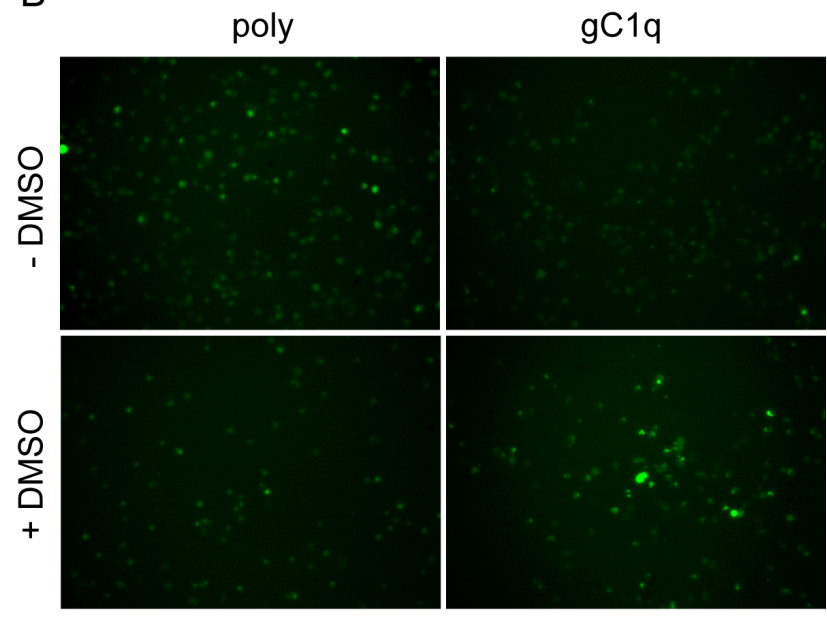

C
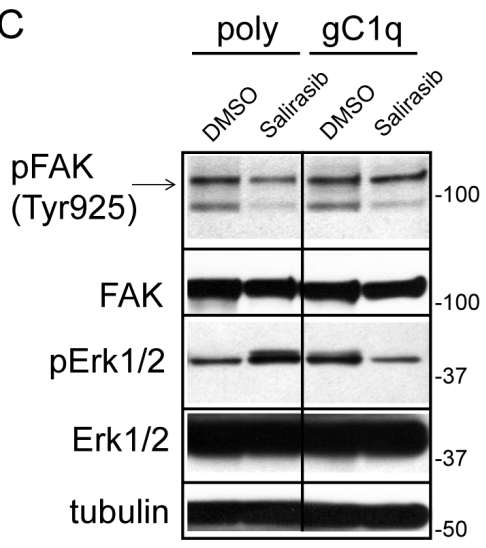

D

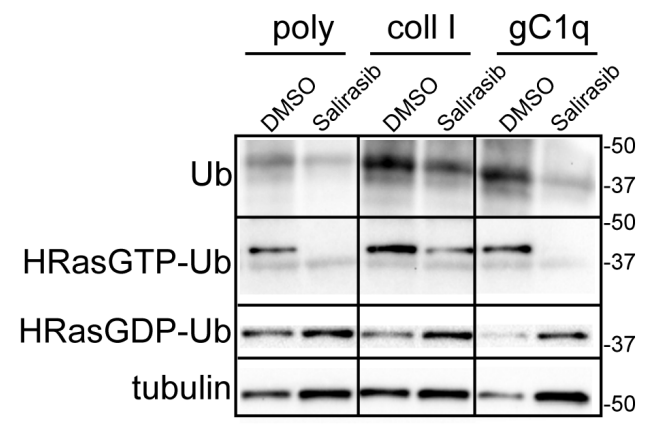

Figure 5: Salirasib/DMSO treatment had opposite effects on cells persistently adherent to polylysine or gC1q. A. Western blot analysis of proteins extracted from HaCat cells 24 hours after plating on polylysine (poly) or gC1q and incubated on a RafGST resin. PAN Ras was used to normalize loading. During the plating the cells were treated (for 24 hours) with DMSO (as vehicle) or salirasib. B. Cytoplasmic $\mathrm{Ca}^{2+}$ levels decrease in HaCat cells persistently adherent to gClq. HaCat cells were allowed to adhere to gClq or polylysine for 24 hours in the absence or in the presence of DMSO; the day after cells were loaded with Fluo-4 AM and the fluorescence intensity was measured by a time lapse instrument. Original magnification 20X. C. HaCat cells were lysed 24 hours after plating on polylysine (poly) or gC1q coated plates and treated with DMSO or salirasib. The blots were incubated with the indicated antibodies (see under Material and Methods). D. Western blot analysis of proteins extracted from HaCat cells 24 hours after plating on poly, coll I or $\mathrm{gClq}$, treated with DMSO or salirasib and incubated on a Raf-GST resin. Note that salirasib/DMSO effect on di-ubiquitinated HRasGTP is dependent on the coating. Tubulin was used as loading control. 
signalling produced by $\alpha 4$ integrin engagement loses its antiproliferative cues.

\section{DISCUSSION}

We demonstrated here that epithelial cells expressing the $\alpha 4 \beta 1$ integrin and persistently engaged in vitro with the ECM glycoprotein EMILIN1/gC1q promoted an integrindependent downregulation of HRas signaling. This in turn led to the downregulation of pERK1/2 proliferation signals (see Figure 7 for a schematic representation). The persistent cell adhesion in vitro is reminiscent of the in vivo condition in which cells are in continuous relationship with the constituents of the ECM. The present findings further explain the peculiar role played by EMILIN1 in the maintenance of cell growth homeostasis in the skin [17]. The EMILIN1/ $\alpha 4 \beta 1 /$ HRas/pERK1/2 pathway was specific for the $\alpha 4 \beta 1 /$ EMILIN1 pair since cells persistently

A

HT2 $\alpha 4$ wt

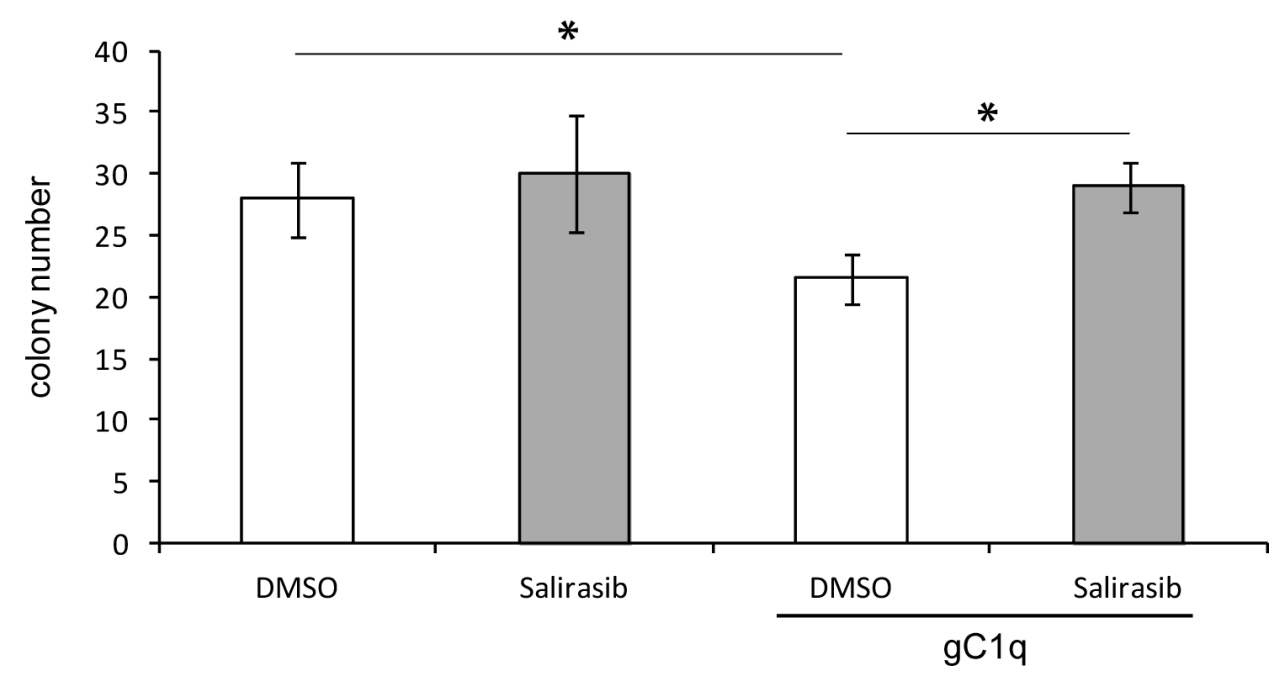

B

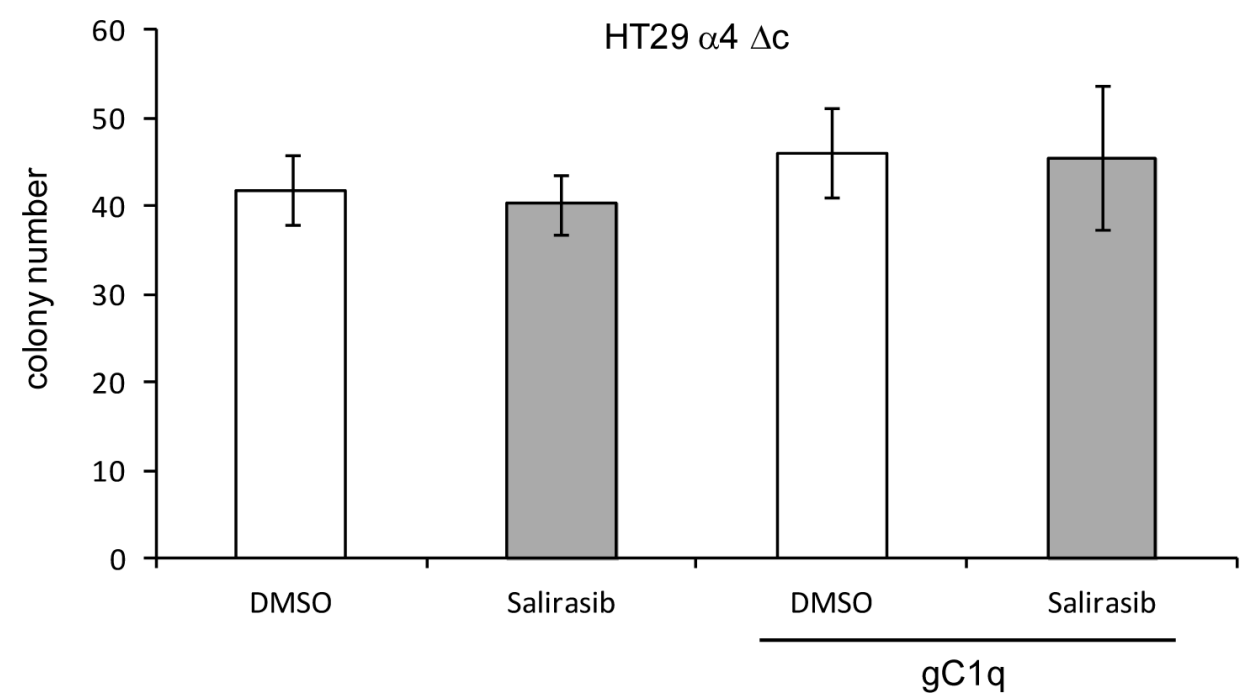

Figure 6: Cells growth in the presence of $\mathbf{g C 1 q}$ is rescued by salirasib. A. HT29 cells transfected with the wild type (wt) or B. the deleted $(\Delta \mathrm{c}) \alpha 4$ integrin chain and plated in $0.4 \%$ agar in the presence or in the absence of $\mathrm{gC} 1 \mathrm{q}$ and treated with salirasib or DMSO as control. ${ }^{*}, \mathrm{P}<0.05$. 
adherent to collagen type I via the $\alpha 2 \beta 1$ integrin did not show enhanced HRasGTP degradation: consequently, the levels of pERK1/2 were unchanged and the cell proliferation was not affected. Moreover, the finding that the $\alpha 4$ integrin chain was co-immunoprecipitated with HRas-Ub only in cells adherent to $\mathrm{gClq}$ and not to polylysine nor to collagen type I indicated that there was a physical association between the $\alpha 4$ integrin chain and HRas-Ub. The reduction of the downstream signaling by HRas required the full integrity of the $\alpha 4$ integrin chain as HT29 cells transfected with a truncated integrin $\alpha 4$ chain were unable to promote HRasGTP ubiquitination and to affect ERK1/2 phosphorylation and hence cell proliferation.

The fact that in $\mathrm{HaCaT}$ keratinocytes persistently adherent on $\mathrm{gClq}$ the salirasib vehicle DMSO increased the low basal $\mathrm{Ca}^{2+}$ level leading to reduced HRasGTP-Ub and increased pERK1/2, while the opposite was observed on polylysine, indicates that the effects of DMSO were specifically linked to the $\alpha 4 \beta 1$ integrin activation by the
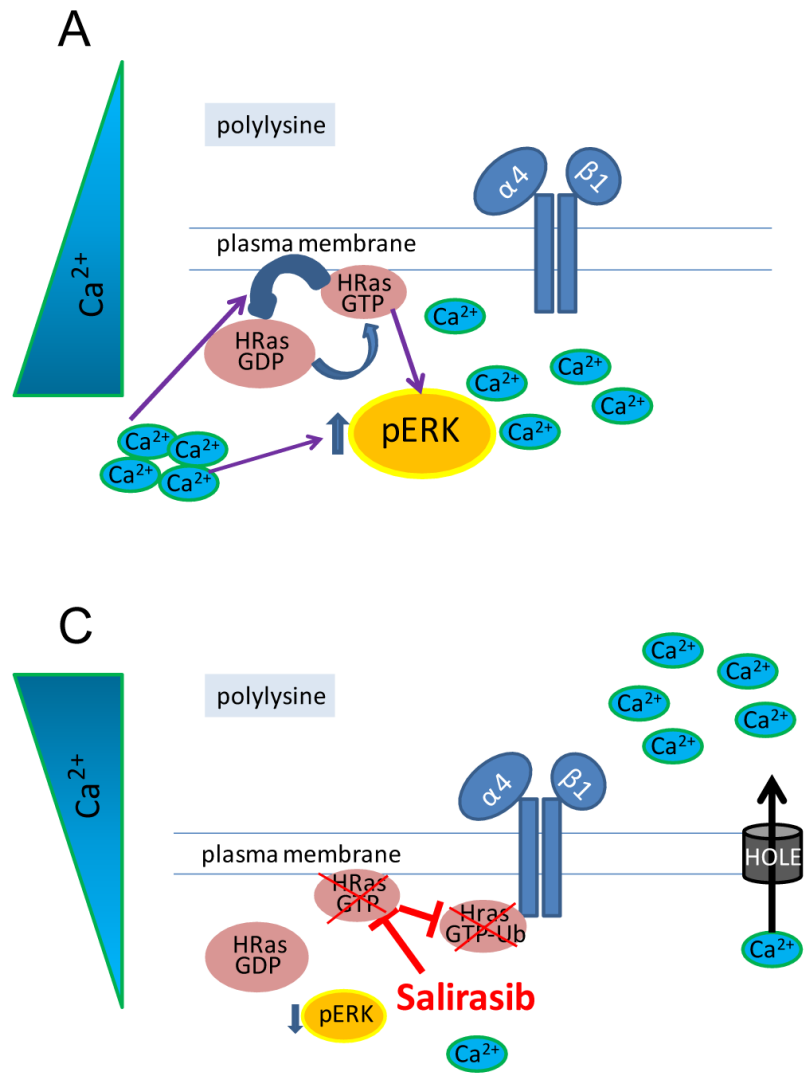

$\mathrm{gC} 1 \mathrm{q}$ ligand. DMSO can induce transient water pores in cell membranes increasing permeability [29]. $\mathrm{Ca}^{2+}$ can easily flow through these pores $[30,31]$. It is noteworthy that free cytosolic $\mathrm{Ca}^{2+}$ is a positive regulator of Ras GTPase Activating Proteins (GAPs) such as CAPRI and RASAL that are responsible for converting HRasGTP to HRasGDP [32-34]; it reduces the levels of HRasGTP and thus of RAS-dependent ERK phosphorylation [35]. Salirasib, which interferes with membrane achoring of HRas, reverted the downstream effects caused by DMSO on persistently adherent cells.

The salirasib-induced reduction in the amount of HRasGTP was the consequence of its dislodgment with increased cytosolic HRasGDP form. Nevertheless, the activation of the $\alpha 4 \beta 1$ integrin after engagement by gC1q and the ubiquitination of HRasGTP downregulated cell proliferation under both $2 \mathrm{D}$ and $3 \mathrm{D}$ conditions.

In conclusion, the $\alpha 4 \beta 1$ integrin engagement by the $\mathrm{gClq}$ triggers a series of events leading to the ubiquitination and degradation of HRasGTP. In turn,

B
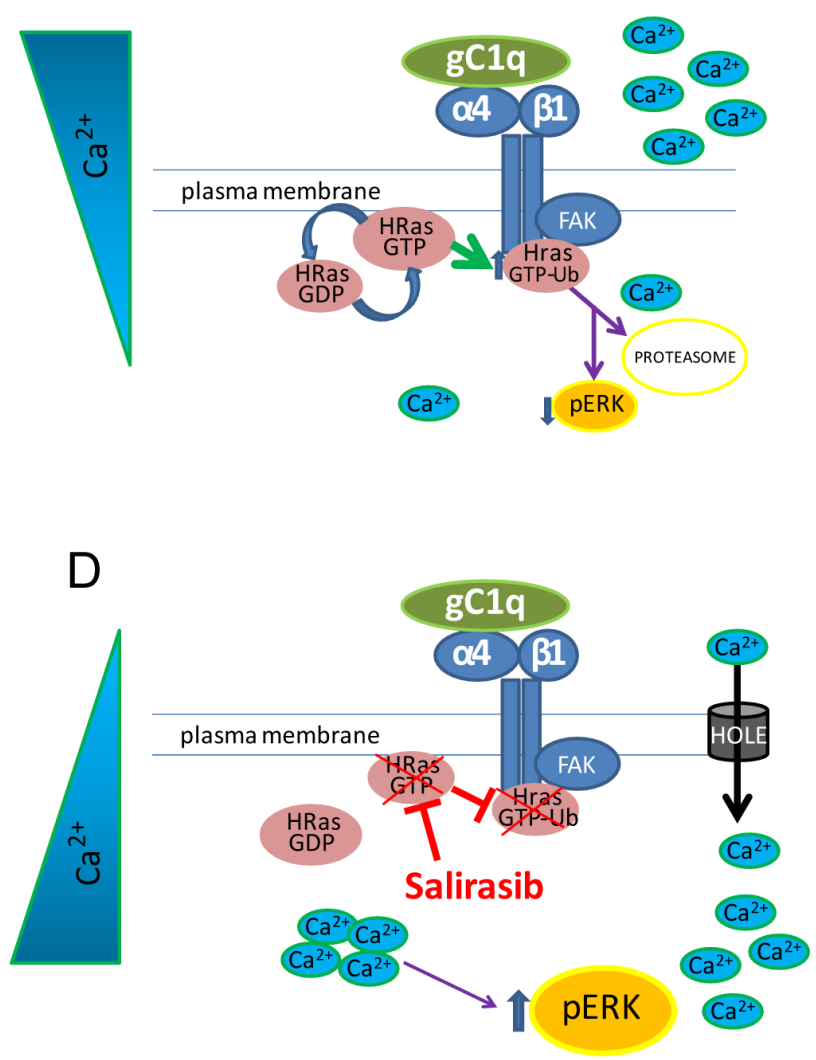

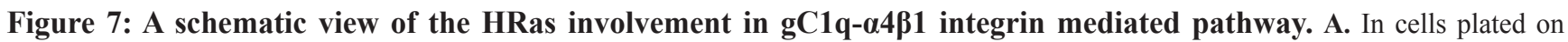
polylysine the $\alpha 4 \beta 1$ inactive integrin is not able to induce HRas activation. High basal level of intracellular $\mathrm{Ca}^{2+}$ is known to modulate the activity of RAS and to activate ERK1/2. B. Activation of $\alpha 4 \beta 1$ integrin, mediated by gC1q, through FAK induces HRasGTP increase as well as its ubiquitination (HRasGTP-Ub). HRasGTP switching off along with low basal level of intracellular $\mathrm{Ca}^{2+}$ is able to reduce ERK1/2 phosphorylation and proliferation. C, D. Salirasib dislodges HRas from plasma membrane preventing its activation and ubiquitination. On the other hand, low levels of cytoplasmic $\mathrm{Ca}^{2+}$, in cells plated on polylysine, lead to low ERK1/2 phosphorylation; on the contrary, high levels of cytoplasmic $\mathrm{Ca}^{2+}$, in cells plated on $\mathrm{gClq}$ rescue the level of $\mathrm{pERK} 1 / 2$. 
the loss of HRasGTP is responsible for $p E R K 1 / 2$ downregulation and low proliferation linking the antiproliferative capability of $\alpha 4 \beta 1$ integrin to a protooncogene like HRas through the switching off of its activated form.

\section{MATERIALS AND METHODS}

\section{Cells and extracellular matrix ligands}

HaCat (immortalized human keratinocytes) cell line was kindly provided by Dr. Lawrence Banks (ICGEB, Trieste). The human HT29 and SW480 colon cancer cells were obtained from the American Type Culture Collection (Rockville, MD). These cells were maintained in continuous culture in humidified $5 \% \mathrm{CO}_{2}$ at $37^{\circ} \mathrm{C}$ using DMEM (Life Technologies, Inc., Gaithersburg, MD) supplemented with glutamine, antibiotics and $10 \%$ heat-inactivated FCS (Gibco, Thermo Fisher Scientific, Waltham, MA USA). Rat tail collagen type I (BD, Biosciences, San Jose, CA) and recombinant gC1q prepared as extensively described by us [12] were diluted in PBS at the final concentration of $10 \mu \mathrm{g} / \mathrm{ml}$ and incubated on plastic dishes overnight at $4 \mathrm{C}$. Polylysine (Sigma-Aldrich, Inc., Milan, Italy) used as control was used at the same concentration.

\section{Protein extraction and immunoblotting}

Cells were starved in DMEM without FCS and then harvested by trypsinization and incubated in complete medium for $1 \mathrm{~h}$ at $37^{\circ} \mathrm{C}$ to allow the re-expression of the membrane integrins. Cells were then washed in DMEM without FCS, resuspended in DMEM and plated for $24 \mathrm{~h}$ on dishes previously coated with collagen type I or $\mathrm{gC} 1 \mathrm{q}$ or polylysine as control. In some experiments cells were treated with $28 \mu \mathrm{M}$ salirasib (Cayman Chemical Company, Cayman) in DMSO. After the desired time, the cells were lysed in $50 \mathrm{mM}$ Tris- $\mathrm{HCl}, \mathrm{pH} 7.5,100 \mathrm{mM}$ $\mathrm{NaCl}, 5 \mathrm{mM} \mathrm{MgCl}, 10 \%$ glycerol, $0.1 \% \mathrm{NP} 40,50 \mathrm{mM}$ $\mathrm{NaF}, 1 \mathrm{mM} \mathrm{Na} \mathrm{VO}_{4}, 1 \mathrm{mM}$ EDTA, $50 \mathrm{mM}$ DTT, 25X Complete Protease Inhibitor Cocktail (Roche, Basilea, Switzerland) buffer on ice for 30 minutes. The samples were then centrifuged $\left(13,000 \mathrm{x} g\right.$ for 30 minutes at $\left.4^{\circ} \mathrm{C}\right)$. The isolated proteins of the supernatant were quantified using the Biorad Protein Assay (Biorad, Hercules, California USA). Total cell lysates were separated on precasted 4-20\% gels (Biorad), followed by Western Blot (GE Healthcare, Little Chalfont, UK) incubated for $1 \mathrm{~h}$ at room temperature in Tris- $\mathrm{HCl}$ and Tween $20(50 \mathrm{mM}$ Tris-HCl, $150 \mathrm{mM} \mathrm{NaCl}, 0.1 \%$ Tween 20, pH 7.5) and 5\% Non-fat Dry Milk (Biorad). The antibodies used according to the protocols supplied by the manufacturer's were the following: pFAK (Tyr925), ERK, pERK1/2 and $\alpha 4$ C-terminal integrin chain from Cell Signaling (Danvers, MA 01923); pFAK (Tyr397) from Invitrogen (Carlsbad,
CA); FAK from BD Biosciences (San Jose, CA); HRas, Ubiquitin and $\alpha 4 \mathrm{~N}$-terminal integrin chain from Santa Cruz (Dallas, TX); Alpha tubulin from Sigma (Milan, Italy). The proteins were then decorated using horseradish peroxidase-conjugated anti-mouse or anti-rabbit antibodies (GE Healthcare) and autoradigraphed by Immobilion Western Chemoluminecsent HRP Substrate (Millipore, Darmstadt, Germany) or analyzed on Biorad Chemidoc Touch Imaging System and quantified by Quantity One Software densitometry or by Biorad ImageLab.

\section{Construction of a cytoplasmic tail deleted $\alpha 4$ integrin chain}

The cytoplasmic tail-deleted $\alpha 4$ chain mutant R974 was generated by introducing a termination codon after residue R974 into che cDNA by PCR. The full-length $\alpha 4$ integrin chain cloned into the Bluescript vector was used for amplification of the 1-974 region of the $\alpha 4$ integrin chain ( $\alpha 4$ forward: 5'ggctcgagccatggettgggaag cgaggcgecg3', including a XhoI restriction site followed by a "kozak" consensus sequence at the 5'-end, and $\alpha 4$ reverseTM 5'ggctggcttctttaaaagataatctagagg3' including a $\mathrm{XbaI}$ and $\mathrm{XhoI}$ restriction sites) and then subcloned in the pcDNA 3.1 vector (Invitrogen). A clone carrying the insert was sequenced and used in the subsequent experiments. The vectors were transfected into HT29 and SW480 cells using FuGENE HD Transfection Reagent (Promega, Madison, WI) following the manufaturer's protocol. To confirm successful transfection, cell extracts of $\alpha 4$-transfected cells were analyzed by Western Blot analysis using anti $\mathrm{N}$ - and anti C-terminal integrin $\alpha 4$ antibodies. To perform experiments with cells uniformly expressing the $\alpha 4$ integrin chain, (more than 95\% positive cells), cells were sorted twice by flow cytometry under sterile conditions in a FACS Canto (Becton Dickinson, Franklin Lakes, NJ) using a specific antibody (PE anti-human CD49d; BioLegend, Pacific Heights, San Diego, CA).

\section{HRas pull down assay}

The DH5alpha bacterial strain was transformed with a pGEX-2T bacterial expression vector encoding GST followed by the 2-149 N-terminal residues of human Raf1 and induced to overexpress the protein by $0.1 \mathrm{mM} \mathrm{IPTG}$ treatment overnight at RT under shaking. This plasmid contains the RAS-binding domain (RBD) that binds only to activated Ras-GTP (gift of Channing Der, Addgene plasmid \#13338). GST-Sepharose resin (GE Healthcare) was washed in cold PBS and incubated under shaking for $2 \mathrm{~h}$ at $4{ }^{\circ} \mathrm{C}$ with total bacterial proteins to allow Raf-RBD conjugation with the resin. The resin was then washed and incubated with cell lysates under shaking for $1 \mathrm{~h}$ at $4^{\circ} \mathrm{C}$. At the end of the incubation, loading buffer $(0.25 \mathrm{M}$ Tris- $\mathrm{HCl} \mathrm{pH}$ 6.8, 10\% SDS, $0.5 \mathrm{M}$ dithiothreitol (DTT), 
$50 \%$ glycerol, $0.25 \%$ bromophenol blue) was added to each sample before protein denaturation by boiling for 10 minutes. The samples were then loaded onto $4-20 \%$ gels followed by Western Blot analysis.

\section{Soft agar colony formation assay}

For the bottom layer $2 \mathrm{ml}$ of $0.6 \%$ agar (Sigma) dissolved in PBS and diluted in DMEM with or without $10 \mu \mathrm{g} / \mathrm{ml} \mathrm{gC1q}$ were allowed to polymerize on 6 well

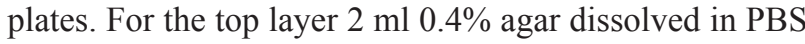
and diluted in DMEM with or without $10 \mu \mathrm{g} / \mathrm{ml} \mathrm{gC1q}$ were allowed to polymerize. $28 \mu \mathrm{M}$ salirasib in DMSO or DMSO used as negative control was added to both agar solutions before polimerization. Before mixing with the top agar layer, $5.0 \times 10^{4}$ HT29 cells transfected with the wild type or the deleted mutant $\alpha 4$ integrin chain were resuspended in DMEM containing 10\% FCS and mixed with the top agar solution. Cells were allowed to grow for 12 days.

\section{Proliferation assays}

To quantitatively monitor cell behavior in real time, we adopted the xCELLigence technology provided by the Real-Time Cell Analyzer dual plate instrument (Roche) [36]. The cell index, an arbitrary measurement and a reflection of overall cell number, attachment quality, and cell morphology can change as a function of time. For proliferation assays, the E-Plates 96 (Roche) were coated with EMILIN1, gC1q or collagen type I $(20 \mu \mathrm{g} / \mathrm{ml})\left(4^{\circ} \mathrm{C}\right.$, overnight). Cells were then seeded at $5 \times 10^{3}$ cells/well in $10 \%$ FCS-containing medium. Cells were monitored every hour for 48 hours. Data analysis was performed using Real-Time Cell Analyzer software (version 1.2) supplied with the instrument. Experiments were performed in triplicate.

\section{Determination of the cytoplasmic $\mathrm{Ca}^{2+}$ levels}

HaCat cells were starved in DMEM without FCS and then harvested by trypsinization and incubated in complete medium for 1 hour at $37^{\circ} \mathrm{C}$. Cells were then washed in DMEM without FCS, resuspended in DMEM and plated for 24 hours on a 96 well plate previously coated with $\mathrm{gClq}$ or polylysine in the presence or in the absence of DMSO. The following day, the cells were loaded with $5 \mathrm{mM}$ Fluo-4 AM (Invitrogen) in DMSO according to the manufacturer's instructions. Fluorescence intensity of the time lapse images was acquired every 45 min during a period of 6 hours using the AF6000 LX workstation Leica.

\section{Cell adhesion assay}

The quantitative cell adhesion assay used in this study is based on centrifugation and has been extensively described [37]. Cells were labeled with the vital fluorochrome calcein AM (Invitrogen) for $15 \mathrm{~min}$ at $37^{\circ} \mathrm{C}$ and then aliquoted into the bottom CAFCA (Centrifugal Assay for Fluorescence-based Cell Adhesion) miniplates at a density of 2.0 to $5.0 \times 10^{5}$ cells $/ \mathrm{ml}$. CAFCA miniplates were centrifuged at $1,000 \mathrm{rpm}$ for $5 \mathrm{~min}$ at $37^{\circ} \mathrm{C}$ to synchronize the contact of the cells with the substrate. The miniplates were then incubated for $20 \mathrm{~min}$ at $37^{\circ} \mathrm{C}$ and subsequently centrifuged at $500 \mathrm{rpm}$. The relative number of cells bound to the substrate (i.e. remaining in the wells of the bottom miniplates) was estimated by top/ bottom fluorescence detection in a computer-interfaced InfiniteM1000 PRO miniplate reader (TECAN Group LTD, Mannedorf, CH).

\section{Statistical methods}

Plotted values are shown as means \pm standard deviation. Statistical significance of the results was determined by using the two-tailed unpaired Student's $t$ test to determine whether two datasets were significantly different. A value of $\mathrm{P}<0.05$ was considered significant.

\section{ACKNOWLEDGMENTS}

We thank Bruna Wassermann and Francesco Bucciotti for their technical help.

\section{CONFLICTS OF INTEREST}

No conflicts of interest regarding sources of financial support, corporate involvement, patent holding etc. has to be disclosed for the present study.

\section{FUNDING}

This study was supported by AIRC (IG 14192) and Ministry of Health (RF-2010-2309719) grants to PS and AIRC (IG-13126) grant to AC.

\section{Author contributions}

TME.M. and P.S. conceived and designed the study; O.M., G.S., A.Ca., E.P. and R.D. developed methodology and performed in vitro experiments; A. C. and P. S. reviewed and interpreted data; TME.M. and P.S. analyzed data and supervised the study; A. C. and P. S. wrote the manuscript. All authors read and approved the final manuscript.

\section{REFERENCES}

1. Moreno-Layseca P, Streuli CH. Signalling pathways linking integrins with cell cycle progression. Matrix Biol. 2014; 34: 144-153. 
2. Sjaastad MD, Lewis RS, Nelson WJ. Mechanisms of integrin-mediated calcium signaling in MDCK cells: regulation of adhesion by IP3- and store-independent calcium influx. Mol Biol Cell. 1996; 7: 1025-1041.

3. Illario M, Cavallo AL, Bayer KU, Di MT, Fenzi G, Rossi G, Vitale M. Calcium/calmodulin-dependent protein kinase II binds to Raf-1 and modulates integrin-stimulated ERK activation. J Biol Chem. 2003; 278: 45101-45108.

4. Downward J. Targeting RAS signalling pathways in cancer therapy. Nat Rev Cancer. 2003; 3: 11-22.

5. Barbacid M. ras genes. Annu Rev Biochem. 1987; 56: 779-827.

6. Baker NM, Der CJ. Cancer: Drug for an 'undruggable' protein. Nature. 2013; 497: 577-578.

7. Oliff A. Farnesyltransferase inhibitors: targeting the molecular basis of cancer. Biochim Biophys Acta. 1999; 1423: C19-C30.

8. Cox AD, Der CJ. Farnesyltransferase inhibitors and cancer treatment: targeting simply Ras? Biochim Biophys Acta. 1997; 1333: F51-F71.

9. Colombatti A, Bressan GM, Castellani I, Volpin D. Glycoprotein 115, a glycoprotein isolated from chick blood vessels, is widely distributed in connective tissue. J Cell Biol. 1985; 100: 18-26.

10. Doliana R, Mongiat M, Bucciotti F, Giacomello E, Deutzmann R, Volpin D, Bressan GM, Colombatti A. EMILIN, a component of the elastic fiber and a new member of the $\mathrm{C} 1 \mathrm{q} /$ tumor necrosis factor superfamily of proteins. J Biol Chem. 1999; 274: 16773-16781.

11. Colombatti A, Doliana R, Bot S, Canton A, Mongiat M, Mungiguerra G, Paron-Cilli S, Spessotto P. The EMILIN protein family. Matrix Biol. 2000; 19: 289-301.

12. Mongiat $M$, Mungiguerra $G$, Bot $S$, Mucignat MT, Giacomello E, Doliana R, Colombatti A. Self-assembly and supramolecular organization of EMILIN. J Biol Chem. 2000; 275: 25471-25480.

13. Spessotto P, Cervi M, Mucignat MT, Mungiguerra G, Sartoretto I, Doliana R, Colombatti A. beta 1 Integrindependent cell adhesion to EMILIN-1 is mediated by the gC1q domain. J Biol Chem. 2003; 278: 6160-6167.

14. Danussi C, Spessotto P, Petrucco A, Wassermann B, Sabatelli P, Montesi M, Doliana R, Bressan GM, Colombatti A. Emilin1 deficiency causes structural and functional defects of lymphatic vasculature. Mol Cell Biol. 2008; 28: 4026-4039.

15. Danussi C, Del Bel BL, Pivetta E, Modica TM, Muro A, Wassermann B, Doliana R, Sabatelli P, Colombatti A, Spessotto P. EMILIN1/alpha9beta1 integrin interaction is crucial in lymphatic valve formation and maintenance. Mol Cell Biol. 2013; 33: 4381-4394.

16. Pivetta E, Wassermann B, Del Bel BL, Danussi C, Modica TM, Maiorani O, Bosisio G, Boccardo F, Canzonieri V, Colombatti A, Spessotto P. Local inhibition of elastase reduces EMILIN1 cleavage reactivating lymphatic vessel function in a mouse lymphoedema model. Clin Sci (Lond). 2016; 130: 1221-1236.

17. Danussi C, Petrucco A, Wassermann B, Pivetta E, Modica TM, Belluz LB, Colombatti A, Spessotto P. EMILIN1- $\alpha 4 /$ $\alpha 9$ integrin interaction inhibits dermal fibroblast and keratinocyte proliferation. J Cell Biol. 2011; 195: 131-145.

18. Walker JL, Assoian RK. Integrin-dependent signal transduction regulating cyclin D1 expression and G1 phase cell cycle progression. Cancer Metastasis Rev. 2005; 24 : 383-393.

19. Gilcrease MZ. Integrin signaling in epithelial cells. Cancer Lett. 2007; 247: 1-25.

20. Streuli CH. Integrins and cell-fate determination. J Cell Sci. 2009; 122: 171-177.

21. Schlaepfer DD, Hanks SK, Hunter T, van der Geer P. Integrin-mediated signal transduction linked to Ras pathway by GRB2 binding to focal adhesion kinase. Nature. 1994; 372: 786-791.

22. Yonemoto M, Satoh T, Arakawa H, Suzuki-Takahashi I, Monden Y, Kodera T, Tanaka K, Aoyama T, Iwasawa Y, Kamei T, Nishimura S, Tomimoto K. J-104,871, a novel farnesyltransferase inhibitor, blocks Ras farnesylation in vivo in a farnesyl pyrophosphate-competitive manner. Mol Pharmacol. 1998; 54: 1-7.

23. Kohl NE, Mosser SD, deSolms SJ, Giuliani EA, Pompliano DL, Graham SL, Smith RL, Scolnick EM, Oliff A, Gibbs JB. Selective inhibition of ras-dependent transformation by a farnesyltransferase inhibitor. Science. 1993; 260: 1934-1937.

24. Jura N, Scotto-Lavino E, Sobczyk A, Bar-Sagi D. Differential modification of Ras proteins by ubiquitination. Mol Cell. 2006; 21: 679-687.

25. Gutierrez L, Magee AI, Marshall CJ, Hancock JF. Posttranslational processing of p21ras is two-step and involves carboxyl-methylation and carboxy-terminal proteolysis. EMBO J. 1989; 8: 1093-1098.

26. Berridge MJ, Lipp P, Bootman MD. Signal transduction. The calcium entry pas de deux. Science. 2000; 287: 1604-1605.

27. Roderick HL, Cook SJ. Ca2+ signalling checkpoints in cancer: remodelling $\mathrm{Ca} 2+$ for cancer cell proliferation and survival. Nat Rev Cancer. 2008; 8: 361-375.

28. Dolmetsch RE, Lewis RS, Goodnow CC, Healy JI. Differential activation of transcription factors induced by $\mathrm{Ca} 2+$ response amplitude and duration. Nature. 1997; 386: 855-858.

29. He F, Liu W, Zheng S, Zhou L, Ye B, Qi Z. Ion transport through dimethyl sulfoxide (DMSO) induced transient water pores in cell membranes. Mol Membr Biol. 2012; 29: 107-113.

30. Neely A, Hidalgo P. Structure-function of proteins interacting with the alphal pore-forming subunit of highvoltage-activated calcium channels. Front Physiol. 2014; 5: 209. 
31. Morley P, Whitfield JF. The differentiation inducer, dimethyl sulfoxide, transiently increases the intracellular calcium ion concentration in various cell types. J Cell Physiol. 1993; 156: 219-225.

32. Walker SA, Cullen PJ, Taylor JA, Lockyer PJ. Control of Ras cycling by Ca2+. FEBS Lett. 2003; 546: 6-10.

33. Liu Q, Walker SA, Gao D, Taylor JA, Dai YF, Arkell RS, Bootman MD, Roderick HL, Cullen PJ, Lockyer PJ. CAPRI and RASAL impose different modes of information processing on Ras due to contrasting temporal filtering of Ca2+. J Cell Biol. 2005; 170: 183-190.

34. Agell N, Bachs O, Rocamora N, Villalonga P. Modulation of the Ras/Raf/MEK/ERK pathway by $\mathrm{Ca}(2+)$, and calmodulin. Cell Signal. 2002; 14: 649-654.
35. Cullen PJ, Lockyer PJ. Integration of calcium and Ras signalling. Nat Rev Mol Cell Biol. 2002; 3: 339-348.

36. Xing JZ, Zhu L, Jackson JA, Gabos S, Sun XJ, Wang $\mathrm{XB}, \mathrm{Xu} \mathrm{X}$. Dynamic monitoring of cytotoxicity on microelectronic sensors. Chem Res Toxicol. 2005; 18: 154-161.

37. Spessotto P, Lacrima K, Nicolosi PA, Pivetta E, Scapolan M, Perris R. Fluorescence-based assays for in vitro analysis of cell adhesion and migration. Methods Mol Biol. 2009; 522: 221-250. 